\title{
Veinte años de Contrastes (y aún antes)
}

\section{Twenty Years of Contrastes (and even Before)}

\author{
PASCUAL MARTÍNEZ-FREIRE \\ Director de Contrastes. Revista Internacional de Filosofía
}

El presente volumen XX de Contrastes, correspondiente al año 2015, constituye la vigésima entrega de esta revista que inició su andadura en el año 1996.

Sin embargo la revista Contrastes no surgió de la nada, ya que fue la sucesora de la revista Philosophica Malacitana, también editada por el Departamento de Filosofía de la Universidad de Málaga.

Resumiendo los datos históricos son los siguientes.

En 1988 apareció Philosophica Malacitana, siendo Pascual Martínez-Freire su director, Juan Fernando Ortega Muñoz y José Rubio Carracedo sus secretarios, y Antonio Javier Diéguez Lucena su secretario administrativo. Esta revista del Departamento de Filosofía de la Universidad de Málaga pervivió hasta 1995, con algún cambio en el Consejo de Dirección, a saber, desde 1991 a 1995 José Rubio Carracedo pasó a director mientras que Pascual Martínez-Freire pasó a secretario, y asimismo Antonio Javier Diéguez Lucena fue sustituido, como secretario administrativo, por Luis de Santiago Guervós.

Philosophica Malacitana publicaba un volumen anual con un solo número, aunque desde 1993 a 1995 se publicaba además un suplemento monográfico por año.

(C) Contrastes. Revista Internacional de Filosofia, vol. XX-N² (2015), pp. 391-393. ISSN: 1136-4076

Departamento de Filosofía, Universidad de Málaga, Facultad de Filosofía y Letras Campus de Teatinos, E-29071 Málaga (España) 
Tras el acuerdo correspondiente del Departamento de Filosofía de la Universidad de Málaga, Philosophica Malacitana fue sustituida en 1996 por Contrastes. Revista Interdisciplinar de Filosofía. Su Consejo de Dirección estaba formado por José Rubio Carracedo como director, Pascual Martínez-Freire y Juan Fernando Ortega Muñoz como subdirectores, José María Rosales Jaime como secretario de redacción, y Luis de Santiago Guervós como secretario de administración.

Desde el volumen del año 2001 hasta 2006 José María Rosales fue sustituido por Manuel Toscano Méndez como secretario de redacción. Asimismo desde el volumen del año 2005 Juan Fernando Ortega Muñoz dejó de ser subdirector.

En el volumen VIII de 2003 la revista pasó a su denominación actual, esto es, Contrastes. Revista Internacional de Filosofía, cambiando el término "interdisciplinar" por el término "internacional".

La revista Contrastes, desde su inicio en 1996 hasta la actualidad, siempre ha publicado un suplemento monográfico por año, además del volumen ordinario. A su vez, el volumen ordinario, a partir de 2008, consta de dos números.

En el volumen XIV de 2009 el Consejo de Dirección fue notablemente modificado. Pascual Martínez-Freire pasó a director (por cese de José Rubio), Juan A. García González fue nombrado vicedirector, Antonio Diéguez Lucena era el secretario de redacción (ya desde el año anterior) y, finalmente, Juan José Padial Benticuaga fue nombrado secretario de administración (por cese de Luis de Santiago).

Finalmente en el volumen XVIII de 2013 el Consejo de Dirección tuvo una última modificación. Pascual Martínez-Freire sigue como director, pero Antonio Diéguez Lucena pasa a director asociado y Juan A. García González continúa como vicedirector. A su vez, José María Atencia Páez es nombrado secretario de redacción y Juan José Padial Benticuaga sigue como secretario de administración.

Aunque estos datos históricos resulten interesantes, más importante es destacar la temática de la revista. Se trata de una revista de filosofía que atiende a los asuntos y temas de las cuatro áreas de conocimiento que componen el Departamento de Filosofía de la Universidad de Málaga, a saber, Filosofía, Filosofía Moral y Política, Lógica y Filosofía de la Ciencia, y Estética y Teoría de las Artes. Actualmente el Consejo Editorial consta de especialistas de estas cuatro áreas, dieciocho en total, de los cuales seis pertenecen a la Universidad de Málaga y doce a otras Universidades. Asimismo, el Consejo Asesor actual está formado por dieciséis personalidades filosóficas, de España y del extranjero, de las cuatro áreas mencionadas.

Tal como indican las normas de publicación, Contrastes sólo admite trabajos originales, preferentemente en español, inglés, francés, alemán y cualquier 
lengua romance. De hecho casi todos los artículos están en castellano. Y es de resaltar la notable contribución de autores iberoamericanos.

En cuanto a la evaluación de los trabajos enviados para su publicación es una evaluación externa y por pares, para lo cual no sólo se recurre a los miembros de los tres Consejos (Dirección, Editorial y Asesor) sino también a otros especialistas de alto rango académico, garantizando que los evaluadores no pertenezcan a la misma Universidad que el autor. Además la evaluación es ciega y puede ser doble o triple.

La tasa de aceptación de Contrastes es buena. Como ejemplo, cabe destacar que Latindex (Sistema Regional de Información en Línea para Revistas Científicas de América Latina, el Caribe, España y Portugal) considera que Contrastes cumple las 33 características exigibles con 0 no cumplidas.

Asimismo cabe destacar que, desde el volumen XVI de 2011, Contrastes tiene firmado un contrato con EBSCO Publishing para su difusión internacional.

Para concluir esta nota conmemorativa de los veinte años de Contrastes, me parece obligado expresar el agradecimiento tanto a los miembros de los Consejos (de Dirección, Editorial y Asesor) de la revista y evaluadores como, ciertamente, a todos los autores de los trabajos publicados durante este tiempo. Unos y otros fueron necesarios. 
